\title{
ALGUNS ASPECTOS DA AVALIAÇÃO DE FAVORABILIDADE EM GEOLOGIA EXPLORATÓRIA
}

\author{
SIDNEI PIRES ROSTIROLLA
}

\begin{abstract}
SOME ASPECTS OF FAVORABILITY EVALUATION IN EXPLORATION GEOLOGY This paper deals with a method of modeling and estimating the favorability in petroleum and mineral exploration. It discusses natural systems analyses, deposit modeling and geomathematical techniques. The basic methodology consists in weighting the diagnostic variables of mineralization and accumulation processes, in order to characterize the necessity and sufficiency of these variables to deposit prediction. The available geological, geochemical and geophysical data are spatially integrated in the selected area, in order to establish the importance of ali variables. Exploration data are integrated in a raster form, using simple geocoded information procedures, according two methods of statistical analysis, a conditional probability approach and a multivariate (principal components) analysis. The modeling and complementary procedures are demonstrated in the Recôncavo Basin, Northeast Brazil, for petroleum, and in the Itaiacoca Formation of Ribeira Belt, Southeast Brazil, for Pb-Zn deposits.
\end{abstract}

Keywords: mineral exploration, petroleum, geomathematics, conditional probability, deposit models.

RESUMO Neste trabalho é discutida uma metodologia para avaliação de favorabilidade em exploração mineral e de petróleo. A estratégia consiste em ponderar as variáveis diagnosticas dos processos mineralizadores ou acumuladores, procurando quantificar seus graus de necessidade e suficiência com base em técnicas geomatemáticas e de modelagem de depósitos. Os dados exploratórios são combinados espacialmente na área selecionada, com o objetivo de estabelecer a importância das variáveis. As informações geológicas, geoquímicas e geofísicas são representadas em forma matricial, sendo integradas através de sistemas de informações geográficas. Estes mapas são combinados, com os ponderadores sendo computados de dois modos: análise probabilística condicional e análise multivariada (componentes principais). As duas técnicas de ponderação e as demais atividades foram demonstradas na Bacia do Recôncavo, nordeste do Brasil, para petróleo e na Formação Itaiacoca do Cinturão Ribeira, sul do Brasil, para depósitos de $\mathrm{Pb}-\mathrm{Zn}$ tipo Mississipy Valley.

Palavras-chave: exploração mineral, petróleo, geomatemática, probabilidade condicional, modelos de depósitos.

INTRODUÇÃO $\mathrm{Na}$ fase inicial de programas exploratórios, a organização do conhecimento geológico é uma etapa fundamental para se hierarquizar os alvos com melhor possibilidade de sucesso. Quando os indícios diretos de depósitos são escassos, a seleção de alvos deve ser baseada na análise e quantificação de variáveis indiretas, o que determina um grau de incerteza muito grande na avaliação. Por exemplo, quando se desenvolve a prospecção em uma determinada região, os níveis georreferenciados de informação que representam as variáveis (layers), podem ser divididos em subáreas (células), nas quais é avaliada a probabilidade da existência de um novo depósito. $\mathrm{O}$ sucesso na prospecção é proporcional ao grau de desenvolvimento do modelo de depósito e à qualidade da informação. Tal situação pode ser quantificada por meio do somatório dos $n$ ponderadores que traduzem o poder de predição das $n$ variáveis reconhecidas na mesma célulaalvo. $\mathrm{O}$ raciocínio considera que a presença de um ou mais guias prospectivos ou anomalias indica, em maior ou menor grau, a possibilidade de existir a jazida.

A avaliação de favorabilidade consiste na associação espacial e análise destas variáveis, que são ponderadas em função de sua importância como guias prospectivos. A sistemática possibilita inferir como a variável considerada está associada ao processo mineralizador ou acumulador e, consequentemente, em que grau ela é indicativa da existência de um bem mineral na região. É importante ressaltar que toda predição, seja qualitativa ou quantitativa, consiste num raciocínio probabilístico, onde o avaliador tenta reduzir o campo de dispersão em torno da sua estimativa.

A utilização de modelos para exprimir a concepção sobre a forma de ocorrência ou sobre a gênese de um depósito mineral, ou de um conjunto deles, tem sido corrente em geologia econômica. Em geral, a formulação múltipla e ambígua desses modelos é decorrente da utilização de dois diferentes planos de informação, mesclados implicitamente: o plano observacional e o plano hipotético. Cada vez mais observa-se a tendência de organizar os elementos utilizados em exploração nos modelos de depósitos minerais (e. $g$. Adams 1986, Mosier \& Bliss 1992), definidos como conjuntos de informações exploratórias construídos empiricamente a partir de depósitos conhecidos, com o objetivo de sistematizar as informacõos pertinentes para a prospecção. De acordo com Henley \& Berger (1993), tais modelos são construídos a partir de características essencialmente geológicas e estão embutidos nos modelos exploratórios, os quais se caracterizam como redes cognitivas derivadas de uma ampla variedade de informações geocientíficas, econômicas e sócio-políticas, com os objetivos de indicar guias para exploração e também dar suporte para decisões da companhia, além de criar uma vantagem competitiva para as empresas. As exigências de uma avaliação mais criteriosa do risco em programas de exploração mineral tomaram parte nas estratégias das empresas, especialmente em decorrência das crise de capital e da competitividade. Em função disto, a decisão vem deixando progressivamente de ser pessoal, para ser uma decisão elaborada com base na análise numérica de dados e em critérios previamente definidos.

O objetivo principal do presente trabalho é a discussão conceituai dessa nova "tecnologia de prospecção", que compreende a modelagem de depósitos e a quantificação de favorabilidade. $\mathrm{O}$ texto está subdividido em três partes: (a) organização da informação, (b) sistemática para quantificação de favorabilidade e (c) exemplos de aplicação na Bacia do Recôncavo, para petróleo, e na Formação Itaiacoca do Cinturão Ribeira, para depósitos de $\mathrm{Pb}-\mathrm{Zn}$ em carbonatos.

\section{ORGANIZAÇÃO DAS INFORMAÇÕES EX- PLORATÓRIAS Construção do Banco de Dados}

O caráter topológico das variáveis torna fundamental a utilização de sistemas de informações georreferenciadas (SIGs) em programas exploratórios. Para representar a posição espacial $x, y$ e o atributo $z$ dos elementos analisados são utilizados modelos matriciais, onde para cada célula é estabelecido um código binário ou Booleano, que registra valor 1 
para interesse positivo e valor 0 para. indefinido ou negativo, dependendo respectivamente da presença ou ausência das evidências favoráveis ao processo mineralizador/acumulador. A seleção das variáveis de interesse, a partir de modelos de depósitos preestabelecidos, constitui a etapa crítica, pois representa as condições de contorno e o domínio de dados utilizados durante a análise numérica posterior. Definidos o modelo de depósito e o seu domínio, os ponderadores podem ser calculados com base na frequência de ocorrência conjunta entre as variáveis diagnosticas e os depósitos conhecidos.

O uso de modelos booleanos é justificado pela distribuição espacial diferenciada de cada variável e pela facilidade decorrente do tratamento numérico através de planilhas. Neste procedimento é utilizada uma matriz, na qual o elemento (pixel) georreferenciado pode ser representado com o valor booleano (caráter 0 ou 1 da variável) e armazenado em tabelas. Os dois estágios principais na avaliação (Fig. 1) são a seleção das variáveis e a quantificação de um ponderador que defina a importância das mesmas.

Análise Sistémica As estratégias baseadas na modelagem de depósitos vêm exigindo uma reorganização tanto na estrutura como no raciocínio utilizado em programas exploratórios, agora com importância crescente na aquisição e
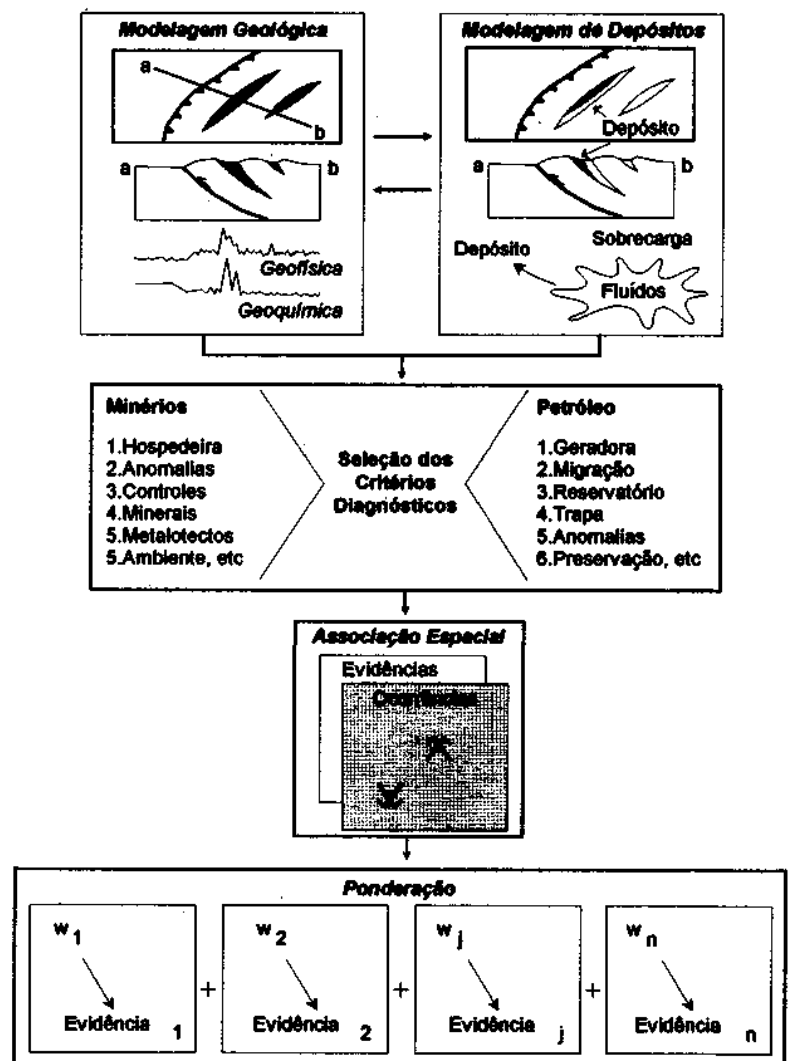

Figura l - Fluxograma representando as atividades para avaliação de favorabilidade em escala regional.

Figure 1 - Flow-chart of favorability regional evaluation activities.

no processamento da informação, ou seja no modus operandi e nos recursos computacionais. Isto coaduna com as abordagens mais recentes em outras áreas científicas, ou seja, cada vez mais utiliza-se a ênfase no processo (ou como fazer) em detrimento do produto. Nesse sentido, o domínio completo em torno da informação força a superação do procedimento clássico adotado na análise metalogenética, havendo a neces- sidade de se desenvolver uma crítica contínua sobre os dados, as técnicas de aquisição, os meios apropriados de processamento, a análise e a interpretação, bem como sobre a eficácia dos critérios prospectivos caracterizados conceitualmente. Embora a avaliação de favorabilidade esteja situada no domínio do desenvolvimento tecnológico, considera-se apropriado individualizar um enfoque organizacional específico para processos naturais, baseado na análise dos sistemas formadores de depósitos, sendo estes definidos como entidades formadas por conjuntos estruturados de objetos e processos interativos, operando com mesma função.

A região onde fatores interagem para produzir uma concentração mineral é considerada um sistema natural com as seguintes características: 1) organização (subsistemas de bombeamento, canalização, transformação, descarga e retroalimentação); 2) composição (matéria - rocha e fluidos, energia, canais de comunicação); 3) estrutura (elementos, dimensão, correlação, causalidade); 4) funcionalidade e 5) macroambiente (Fig. 2). Podem ser concebidos dois níveis hierárquicos de sistemas concentradores. $\mathrm{O}$ nível maior é o sistema metalogenético ou macroambiente, onde ocorrem econômica interativos que promovem a movimentação diferencial e seletiva de matéria mineralizadora e energia. $\mathrm{O}$ nível hierárquico seguinte é o sistema formador de minério (SFM) ou de petróleo (SFP), contido no macroambiente, onde ocorrem processos que promovem a concentração eficaz para produzir depósitos económicos. $\mathrm{O}$ objetivo da análise do sistema metalogenético é a delimitação de sítios com maior potencial de desenvolvimento do SFM ou SFP, que pode ser feita em duas etapas: avaliação regional da favorabilidade e avaliação do prospecto.

Figura 2 - Esquema simplificado de sistemas formadores de
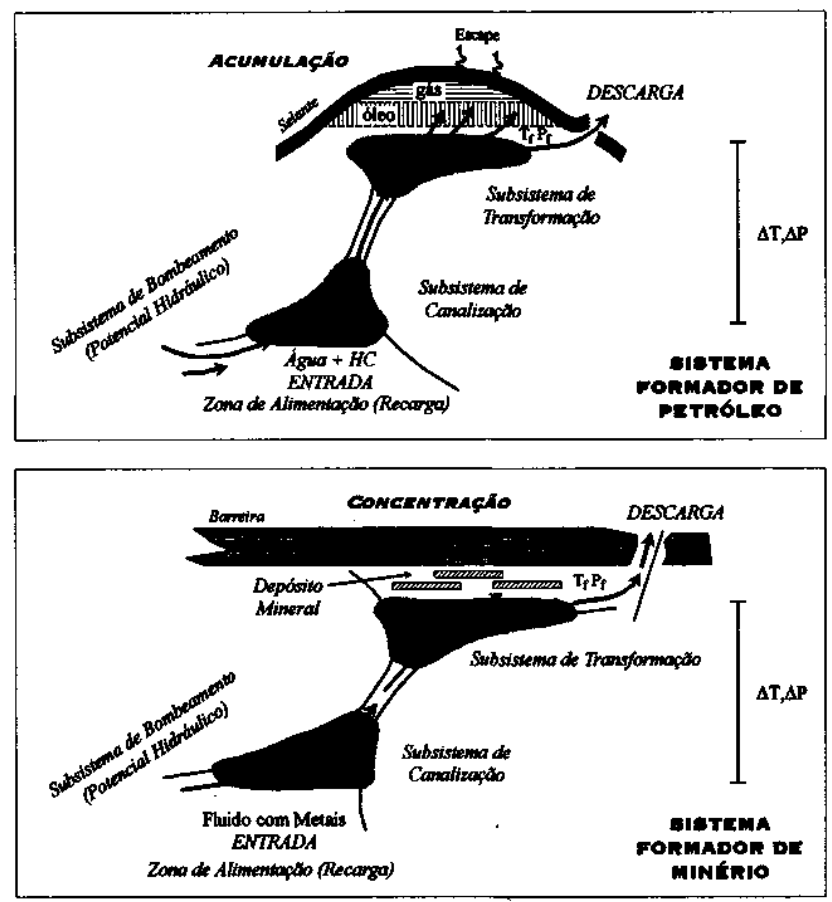

minério e petróleo, mostrando os subsistemas componentes e as transferências de matéria e energia (Ti e Tf: temperatura inicial e final; $P i$ e Pf: pressões inicial e final; $\Delta \mathrm{J}$ e $\Delta \mathrm{P}$ : diferencial de temperatura e pressão entre a entrada e a saída do sistema; modificado de Rostirolla et al 1996). Figure 2 - Simplified model of mineral and petroleum forming systems, showing the componenis ofmbsystems and the transferences of matter and energy - Ti and Tf: initial and final temperature; Pi e Pf: initial and final 
A análise de sistemas formadores de petróleo é um estudo dirigido ao objetivo específico de determinar a favorabilidade de uma região para a descoberta de novos campos. Conforme Magoon \& Dow (1994), a investigação destes sistemas se apoia nas relações genéticas entre um grupo particular de rochas geradoras e o petróleo existente na rocha reservatório, fazendo uso de análises geoquímicas, da estratigrafia e da análise estrutural dos elementos e processos geológicos essenciais. A partir do momento em que este sistema é adequadamente compreendido, e são definidas as suas relações de organização, estrutura, composição e funcionalidade, iniciase a etapa de avaliação de favorabilidade. A importância do estudo de sistemas formadores de petróleo consiste na determinação da eficiência e eficácia dos elementos que indicam os processos formadores de acumulações, tais como a alimentação, migração, trapeamento e produtividade .(fertilidade do sistema), e o intervalo de tempo de sua atividade. Com base na caracterização e interpretação destes elementos, é possível orientar a descrição dos plays (modelos definidos conceitualmente para representar os fatores que produzem acumulações restritas a um determinado nível estratigráfico) e dos prospectos (acumulação potencial, ainda não descoberta), discriminando os fatores geológicos com alto poder de predição.

A análise de sistemas formadores de minérios prioriza a utilização de variáveis diagnosticas, do mesmo modo como os modelos DPC (Data-Process-Criteria, Adams 1986) e os modelos de depósitos de Cox \& Singer (1986), entre outros. $\mathrm{O}$ estudo de SFMs é baseado na definição dos seguintes componentes: 1) variáveis de estado, 2) variáveis motoras, 3 ) variáveis auxiliares e 4) entradas e saídas. As variáveis de estado correspondem aos valores que poderiam ser medidos caso fosse possível congelar a atividade do sistema (gradiente de temperatura, gradiente de pressão e posição $x y z$ do material no espaço). As variáveis motoras são aquelas que movimentam o sistema, afetando mas não sendo afetadas pelas variáveis de estado (gradiente geotérmico regional, estoque de metais e de solventes, potencial redox, movimentações tectônicas). As variáveis auxiliares participam diretamente da atividade das variáveis motoras e podem se interrelacionar (fluxo térmico, canalização e expulsão de fluidos, de metais e de solventes, quantidade de substâncias redutoras na estrutura de aprisionamento). As entradas e saídas compreendem as quantidades de matéria movimentadas entre os pontos de origem e final de transferência de matéria (rocha-fonte e descarga).

Como é difícil estimar as variáveis individualmente, podese considerar grupos de atributos ou parâmetros que descrevem em conjunto as variáveis motoras e auxiliares. Este raciocínio possibilita determinar quatro grupos de variáveis: 1) gradiente de pressão e temperatura (potencial de transporte do fluido $=\mathrm{T}$ ); 2) $\mathrm{pH}$, Eh e salinidade do fluido (potencial de dissolução $=\mathrm{D}) ; 3$ ) teor de metais (volume transportado $=\mathrm{V}$ ) e 4) funções transformadoras para aprisionamento (potencial de precipitação $=\mathrm{P}$ ).

A dinâmica da relação entre o macroambiente e o SFM pode ser descrita pela seguinte equação

$$
R=\frac{T \cdot D}{V \cdot P}
$$

onde $R$ é a razão dispersão/concentração. Uma razão $R$ constante mantém o estado do sistema. $\mathrm{O}$ aumento de $R$ registra a manutenção dos metais no fluido mineralizador e a diminuição condiciona a precipitação e a formação do depósito. A interação entre os grupos de variáveis $T, D, V e P$ caracteriza três regimes: 1) equilíbrio, 2) dominado por dispersão do fluido mineralizador e 3) dominado pela concentração, portanto ideal sob o ponto de vista exploratório.

Admite-se que a quantificação de favorabilidade exige a classificação adequada dos fatores concentradores, com a análise sistémica auxiliando na elaboração do modelo exploratório. Como normalmente inexistem informações diretas sobre a existência do depósito ou acumulação, os critérios diagnósticos obtidos através da análise sistémica são muito úteis como guias exploratórios e, devidamente ponderados, podem conduzir a pesquisa e indicar as áreas preferenciais de busca. A concepção sistémica leva a um caráter multidisciplinar, com o enfoque passando a ser processual, com suporte em estratégias de busca baseadas no conhecimento adquirido. Esta perspectiva favorece o raciocínio completo em torno da informação, e torna a seleção dos prospectos mais criteriosa.

QUANTIFICAÇÃO DE FAVORABILIDADE A etapa inicial da avaliação corresponde à montagem do modelo de ocorrência, quando são discriminadas as evidências favoráveis à concentração (critérios diagnósticos). A segunda etapa corresponde ao entendimento dos sistemas concentradores, que podem ser representados por modelos genéticos. Após isto, é gerado um modelo de probabilidade, onde os valores determinísticos, estruturados segundo o modelo de ocorrência e explicados pelo modelo genético, são transformados em dados estocásticos, utilizando métodos de ponderação de variáveis exploratórias (Rostirolla et al. 1998). Assim, é possível predizer a favorabilidade de um depósito ou de uma acumulação, de tamanho e volume adequados, ocorrer em determinada área-alvo.

Seguindo as premissas definidas por Chung et al. (1992) e Rostirolla et al. (1998), são consideradas "necessárias" aquelas variáveis que sempre existem nos depósitos conhecidos, enquanto as variáveis "suficientes" podem ou não existir em depósitos conhecidos, mas a sua ocorrência representa um forte indício da mineralização (Fig. 3). A condição de suficiência de uma variável (evidência $E$ ) é satisfeita quando a probabilidade de existência do depósito (hipótese $H$ ) é maximizada com a existência da variável $(\mathrm{P}(\mathrm{H} \mid \mathrm{E})=$ máximo $)$. A condição de necessidade da variável é satisfeita quando a probabilidade de não existência do depósito é maximizada com a não existência da variável $((\mathrm{P}(\overline{\mathrm{H}} \mid \overline{\mathrm{E}})=$ máximo $)$.

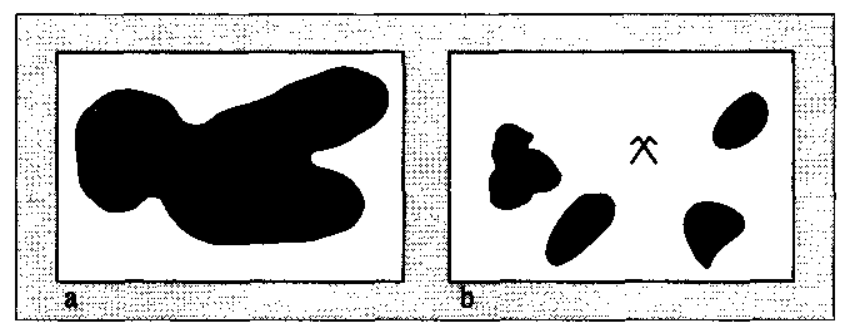

Figura 3 - Representação estatística dos conceitos de necessidade e suficiencia (modificado de Rostirolla et al. 1998). Os símbolos representam os depósitos e a área hachurada a distribuição da variável, onde: a) variáveis necessárias sempre estão presentes nos depósitos conhecidos $e \quad b)$ variáveis suficientes - podem ou não estar presentes, mas quando presentes são bons indicadores dos depósitos. Figure 3 - Statistical representation ofthe necessity and suficiency concepts (modified from Rostirolla et al. 1998). The symbols represem deposita and the hachured area is the distribution of the variable, where: a) necessary variables -are always present in known deposits; b) suficient variables - may or may not be present, but when present are good indicators of deposits. 
Ponderação Bayesiana Nos mapas de variáveis exploratórias, os pontos conhecidos (amostras da população estudada) são tratados como pixels e combinados espacialmente para estimar os valores desconhecidos. A seguir, é apresentado um modelo estatístico baseado em Agterberg (1989) e Bonham-Carter et al (1989), onde o ponderador é definido para permitir a representação das condições de necessidade e suficiência (vide discussão detalhada em Rostirolla et al. 1998).,

Segundo o modelo adotado, em todas as células avaliadas, a chance posterior $C h\left(H \mid E \frac{k}{j}\right)$ de ser encontrado um depósito

(ou hipótese $H$ ) é dada pelo somatório da chance prévia $C h(H)$ com os ponderadores $\mathrm{W} \frac{k}{j}$ referentes às evidências $E \frac{k}{j}$ :

$$
\operatorname{In} C h\left(H \backslash E \frac{k}{j}\right)=\mathrm{w} \frac{k}{j}+\operatorname{In} C h(H)
$$

onde o superíndice $k$ refere-se à presença $(+)$ ou ausência (-) da variável, e os ponderadores $\mathrm{w}_{j}{ }_{j}$ são razões de probabilidade (likelihood ratios) calculados do seguinte modo para cada variável $E_{j}^{k}$

$$
w_{j}^{k}=\ln \frac{P\left(E_{j}^{k} \mid H\right)}{P\left(E_{j}^{k} \mid H\right)}=\ln \frac{\frac{H \cap E_{j}^{k}}{H}}{\frac{\bar{H} \cap E_{j}^{k}}{\bar{H}}},
$$

Todos os níveis georreferenciados adicionais devem ser computados como mapas binários e, para $E j(j=1,2,3, \ldots, n)$ mapas, o somatório é representado pelas fórmulas:

$$
\begin{aligned}
& \ln C h\left(H \mid E_{1}^{k} \cap E_{2}^{k} \cap \ldots \cap E_{n}^{k}=\sum_{j=1}^{n} w_{j}^{k}+\ln C h(H)\right. \\
& \operatorname{Ch}\left(H \mid E_{1}^{k} \cap E_{2}^{k} \cap \ldots \cap E_{n}^{k}\right)=\exp \left\{\sum_{j=1}^{n} w_{j}^{k}+\ln C h(H)\right\}
\end{aligned}
$$

Baseado nos resultados, a probabilidade posterior (ou favorabilidade para cada célula avaliada) pode ser obtida a partir da chance posterior.

Ponderação Multivariada A ponderação multivariada consiste em atribuir pesos para cada critério diagnóstico a partir da análise de componentes principais (ACP), consistindo numa técnica de classificação de objetos (Harff \& Davis 1990). Dentre as variantes deste método estatístico para a exploração, podem ser destacados os trabalhos de McCammon et al. (1983), que enfoca a análise característica, e Pan \& Porterfield (1995), onde a definição de alvos baseia-se na comparação entre as variáveis existentes em células-padrão (depósitos conhecidos) e as variáveis distribuídas regionalmente (área total avaliada).

A favorabilidade é obtida pelo somatório das variáveis regionais expressas em notação binária, ponderadas pêlos coeficientes do autovetor relativo ao maior autovalor, este obtido da matriz original dos dados em células-padrão, do seguinte modo:

$$
F_{1 c}=\sum_{j=1, c=1}^{n, m} w_{1 j} \cdot z_{j c}
$$

onde $w l j$ é a matriz de ponderação, cujos $j$ elementos são os coeficientes do autovetor;

Zjc é a matriz original dos dados transformados ( 0 ou 1$)$, com $j$ variáveis e $c$ células;

Flc é a matriz linha resultante, com os valores de favorabilidade nas $c$ células da área pesquisada.

A ponderação é feita por meio da multiplicação dos coefi- cientes do autovetor (matriz linha) pelos elementos da matriz original (variáveis por células), resultando numa matriz que representa o somatório das ponderações em cada célula. A importância de uma variável expressa em notação binária $(0$ ou 1) decorre da relação espacial com as demais variáveis. Tal relação é quantificada pelo número de coincidências das variáveis tomadas duas a duas na área-padrão (coexistência de variáveis). As relações espaciais entre variáveis e depósitos conhecidos são representadas por uma matriz, onde as linhas são as variáveis e as colunas as células. A multiplicação desse matriz por sua transposta, na ordem de multiplicação (Matriz Original X Matriz Transposta=Matriz Produto), resulta numa matriz que pode ser analisada matematicamente como uma matriz de variância/covariância ou autocorrelação/correlação. Considerando este pressuposto, a contribuição de cada variável para a predição de depósitos não descobertos pode ser calculada de modo semelhante à análise de principais componentes (Carr 1995). No método, as células da área pesquisada representam observações num espaço cujos eixos são as variáveis ou critérios diagnósticos. Nesse espaço existe uma direção (autovetor) relativa ao maior autovalor, na qual todas as coexistências entre variáveis são maximizadas; repetido para todo o conjunto de dados, este procedimento equivale a encontrar a projeção das observações originais sobre as novas variáveis (os componentes principais).

\section{ESTUDOS DE CASO Bacia do Recôncavo Os}

mapas de evidências geológicas utilizados durante a avaliação de favorabilidade na Bacia do Recôncavo estão baseados em Milani (1987), Milani \& Davison (1988), Figueiredo et al. (1994), Mello et al. (1994)eMagnavita et al. (1994). A Bacia do Recôncavo é localizada no nordeste brasileiro (Fig. 4) e corresponde a um rifte abortado de idade Jurássico-Cretácica, formado durante a abertura do Oceano Atlântico Sul. Contém

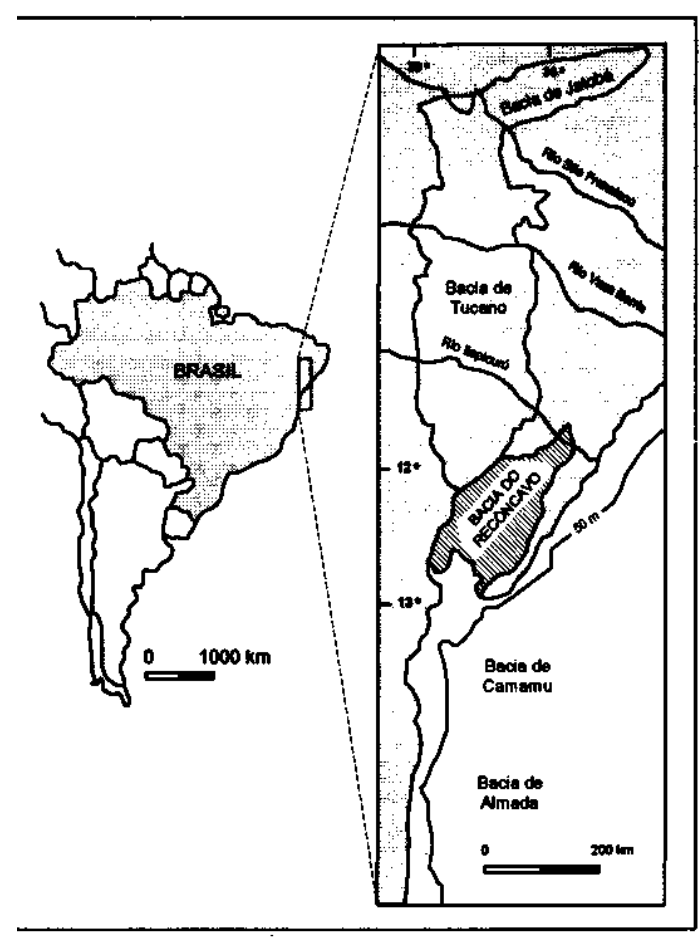

Figura 4 - Mapa de localização da Bacia do Recôncavo (modificado de Figueiredo et al 1994).

Figure 4 - Location map of the Recôncavo Basin (modified from Figueiredo et al 1994). 
cerca de $6.000 \mathrm{~m}$ de rochas sedimentares subdivididas em três sequências deposicionais que, da base para o topo, compreendem: (1) sequência pré-rifte, com depósitos fluviais e aluviais áridos e fácies associadas; (2) sequência sin-rifte, depositada em regime deltaico e aluvial e que representa o assoreamento da bacia no Cretáceo e (3) sequência elástica superior que cobre parcialmente a sequência sin-rifte, embora não relacionada com subsidência térmica (Fig. 5). O arcabouço estrutural é definido por um conjunto de falhas normais que limitam a bacia, sendo a falha de Salvador, situada a sudeste, a principal estrutura controladora da sedimentação. Devido a diferentes taxas de estiramento crustal, a bacia é cortada por falhas transferentes de direção noroeste (falhas de Mata-Catu e Itanagra-Araçás), que a dividem nos compartimentos nordeste, central e sudeste.

O principal nível gerador da bacia do Recôncavo é representado pelos membros Gomo e Tauá, ambos da Formação Candeias, com valores médios de carbono orgânico total em torno de $1 \%$ e potencial gerador médio de $5 \mathrm{~kg}$ de $\mathrm{HC} /$ ton de rocha nas porções mais profundas da bacia, podendo local-

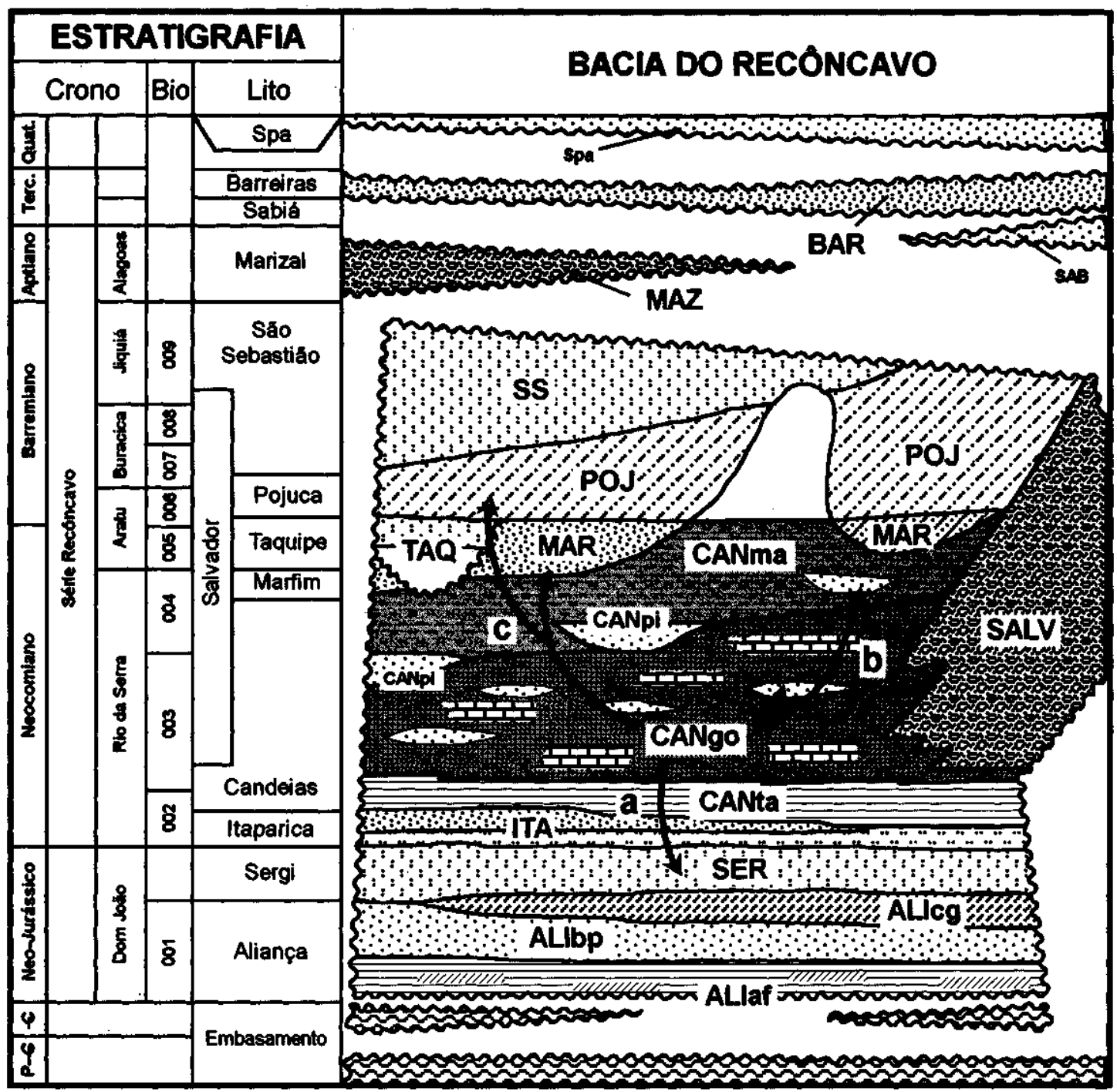

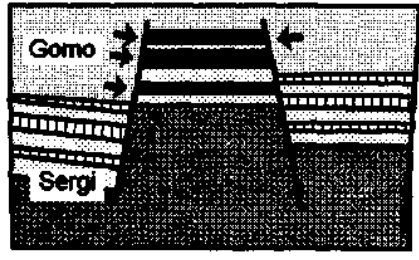

a
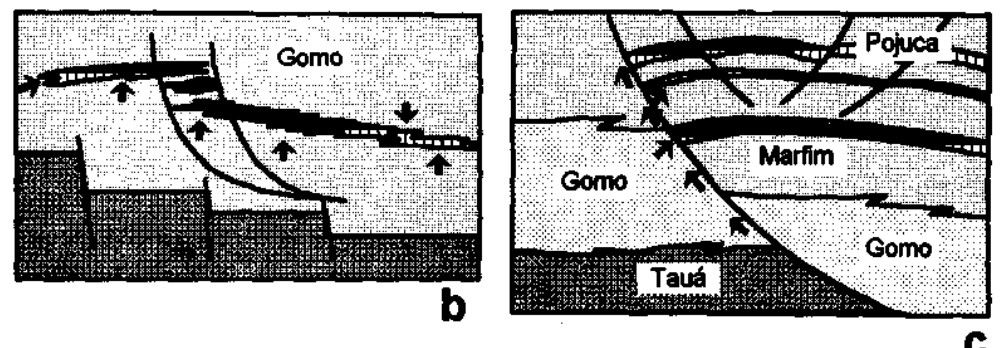

Figura 5 - Carta estratigráfica da Bacia do Recôncavo, com a indicação dos modelos de acumulação: a) trapas estruturais pré-rifte; b) trapas estratigráficas e combinadas sin-rifte Candeias; c) trapas em rollovers sin-rifte Marfim/Pojucas (modificado de Figueiredo et al. 1994).

Figure 5 - Stratigraphic chart of the Recôncavo Basin, with indication of accumulation models: a) pre-rift horst traps; b) sin-rift Candeias stratigraphic and combined traps; c) sin-rift Marfim/Pojuca rollovers traps (modified from Figueiredo et al 1994). 
mente alcançar $10 \mathrm{~kg} \mathrm{HC} /$ ton. A Formação Pojuca também apresenta alto potencial gerador, mas ocorre acima da janela de geração em quase toda a bacia. $\mathrm{O}$ topo da zona matura é encontrado em níveis mais rasos nas margens da bacia, estando as rochas sedimentares da Formação Candeias em estágio senil nos baixos deposicionais. Os arenitos fluviais da seção pré-rifte (Formação Sergi) são o principal nível reservatório do Recôncavo, apresentando um padrão textural de coarsening-upward, porosidade de 10 a $25 \%$ e permeabilidade de 20 a 1.200 md. Os turbiditos da Formação Taquipe caracterizam o segundo mais importante play da bacia, com porosidade de 18 a $24 \%$ e permeabilidade de 30 a 300 md. Secundariamente, níveis arenosos turbidíticos da Formação Candeias (Membro Pitanga) representam um terceiro play, com porosidade de 15 a $18 \%$ e permeabilidade em torno de $30 \mathrm{md}$, ocasionalmente $300 \mathrm{md}$. As rochas sejantes são pelitos capeando os arenitos reservatórios.

Atualmente, são aceitos três modelos de migração e acumulação de petróleo na bacia (Fig. 5): (1) trapas estruturais formadas porhorsts, basculados ou não, onde os reservatórios pré-rifte são alimentados lateralmente a partir de folhelhos geradores localizados nos baixos de falhas normais; (2) trapas estratigráficas ou combinadas, principalmente reservatórios turbidíticos das formações Candeias e Marfim conectados diretamente aos folhelhos geradores, com migração por distâncias pequenas e (3) rollovers formados em baixos de falhas de crescimento da seção sin-rifte, ao nível dos reservatórios deltaicos das formações Pojuca e Marfim, com migração vertical ao longo de falhas regionais.

As variáveis exploratórias foram organizadas em dois conjuntos principais, representados pelas funções de alimentação (geração e migração) e de armazenamento (reservatório e trapeamento), sendo confrontadas com os locais de existência dos campos de petróleo (Fig. 6). Convém salientar que o fator tempo (timing) foi considerado adequado para a formação de acumulações, tendo em vista as descobertas na bacia. As informações exploratórias utilizadas foram as seguintes (Figs 7 e 8):

\section{Fator Geração:}

- Mapa de Isópacas do Membro Gomo (Figueiredo et al. 1994)

- Mapa Bouguer (Figueiredo et al. 1994)

- Mapa de Profundidade do Topo da Zona Matura (Magnavita et al. 1994)

Fator Migração:

- Compartimentos Estruturais (Milani \& Davison 1988)

- Falhas Principais (Milani \& Davison 1988)

- Paleoestrutura do Embasamento (Carozzi et al. 1976)

Fator Reservatório:

- Isópacas da Formação Sergi (Figueiredo et al. 1994)

- Isópacas do Membro Pitanga, Formação Candeias (Figueiredo et al. 1994)

- Isópacas do Membro Caruaçú, Formação Marfim (Figueiredo et al. 1994)

Fator Trapeamento:

- Mapa de Contorno Inferido do Topo da Formação Sergi

- Baixos e Altos Estruturais Associados às Falhas Regionais

- Interface entre Altos e Baixos Estruturais.

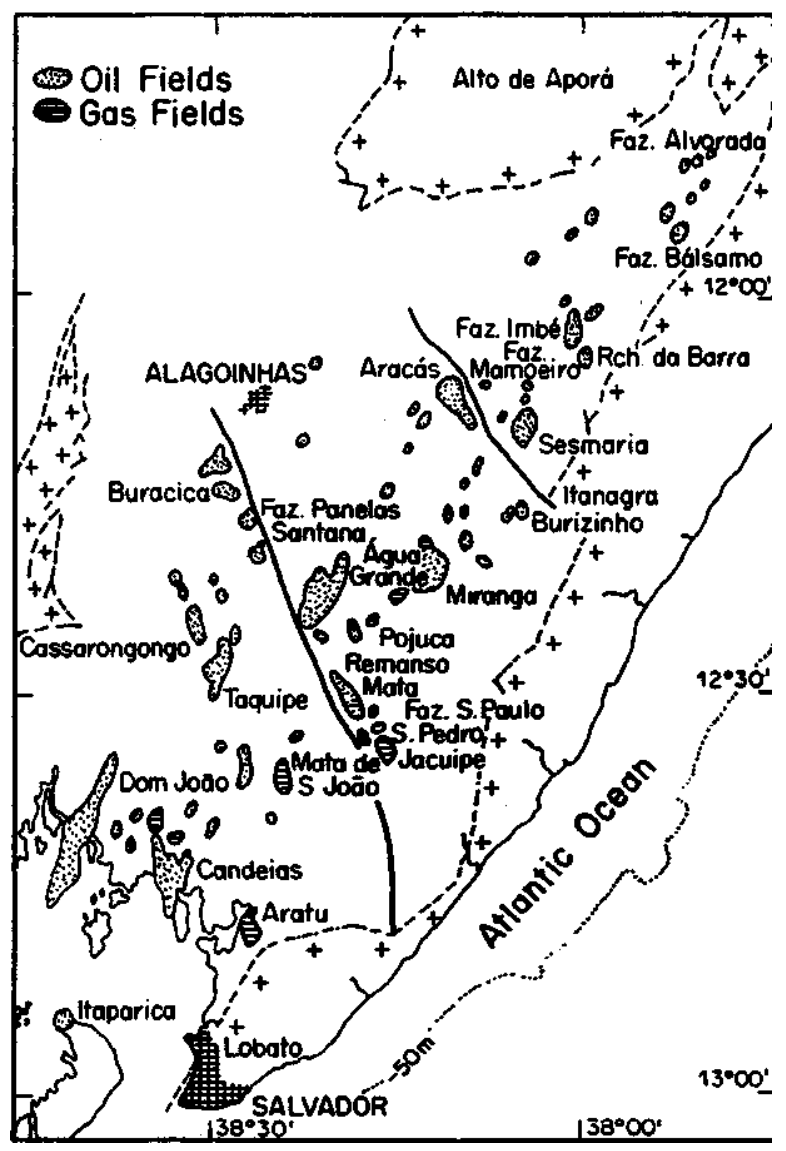

Figura 6 - Mapa dos campos de petróleo (modificado de Figueiredo et al. 1994).

Figure 6 - Map of petroleum fields (modified from Figueiredo et al. 1994).

Para avaliar a favorabilidade da Bacia do Recôncavo, os mapas foram discretizados em variáveis binárias, a partir dos quais foram calculados os ponderadores (Tabela 1). Ambos os métodos priorizam as áreas que contêm grande parte dos campos já descobertos (Figs. 9 e 10). A variável que exerce maior influência para a delimitação de áreas favoráveis é a interface entre baixos e altos estruturais, para a qual foi obtido o maior peso em ambos os métodos. Outras variáveis que influenciaram muito o resultado final foram o topo da zona matura $\left(3^{\mathrm{a}}\right.$ em importância pelo método bayesiano e $9^{\mathrm{a}}$ na análise multivariada) e as isópacas do Membro Caruaçú ( $4^{\mathrm{a}}$ no método bayesiano e $12^{\mathrm{a}}$ na análise multivariada). Além disso, observa-se uma inversão na importância da variável "baixos estruturais" ( $2^{\mathrm{a}}$ pelo método bayesiano e $6^{\mathrm{a}}$ pelo multivariado) e "mapa bouguer" $\left(6^{\mathrm{a}}\right.$ e $2^{\mathrm{a}}$, respectivamente). Tais características foram decisivas na discriminação de locais favoráveis e desfavoráveis, respectivamente aos métodos bayesiano e multivariado. No mapa final, podem ser destacados dois locais para prospecção de semi-detalhe: 1) a norte do campo de Água grande, na Plataforma de Quiricó e 2) entre os campos de Taquipe e Dom João.

Faixa Itaiacoca A Faixa Itaiacoca foi avaliada para depósitos de $\mathrm{Pb}-\mathrm{Zn}$ em carbonatos, numa área com cerca de $85 \mathrm{~km}$ (Fig. 11). A sequência pesquisada compreende as rochas metassedimentares e metavulcânicas da Formação Itaiacoca, próximo ao contato desta com xistos do Grupo Setuva. O mapa geológico simplificado apresenta três associações maiores de rochas (Soares et al. 1987): 1) xistos do Grupo Setuva (Meso-Proterozóico), intrudidos pelo Granito São Domingos (Neoproterozóico); 2) rochas metacarbonáti- 
cas e terrígenas intercaladas a rochas metavulcânicas (Formação Itaiacoca, Neoproterozóico); e 3) cobertura fanerozóica representada pela Formação Furnas. Na região ocorrem diversas falhas com direção principal norte-sul, compreendendo falhas de empurrão de baixo e alto ângulo, transcorrências compressionais e falhas transtensionais ou normais tardias, estas últimas aparentemente sem controle sobre as mineralizações. As falhas de cavalgamento são o principal metalotecto estrutural, seguidas pelas falhas de empurrão e transcorrentes do evento compressivo, sendo a estrutura mais pronunciada a falha do Rio Itararé, que limita a Formação Itaiacoca com os xistos.

As mineralizações de $\mathrm{Pb}, \mathrm{Zn}$ e $\mathrm{Cu}$ estão relacionadas aos mármores basais da Formação Itaiacoca (Stevanato et al 1991). Na seção mineralizada predominam rochas deformadas por cisalhamento de baixo e alto ângulos e metamor-

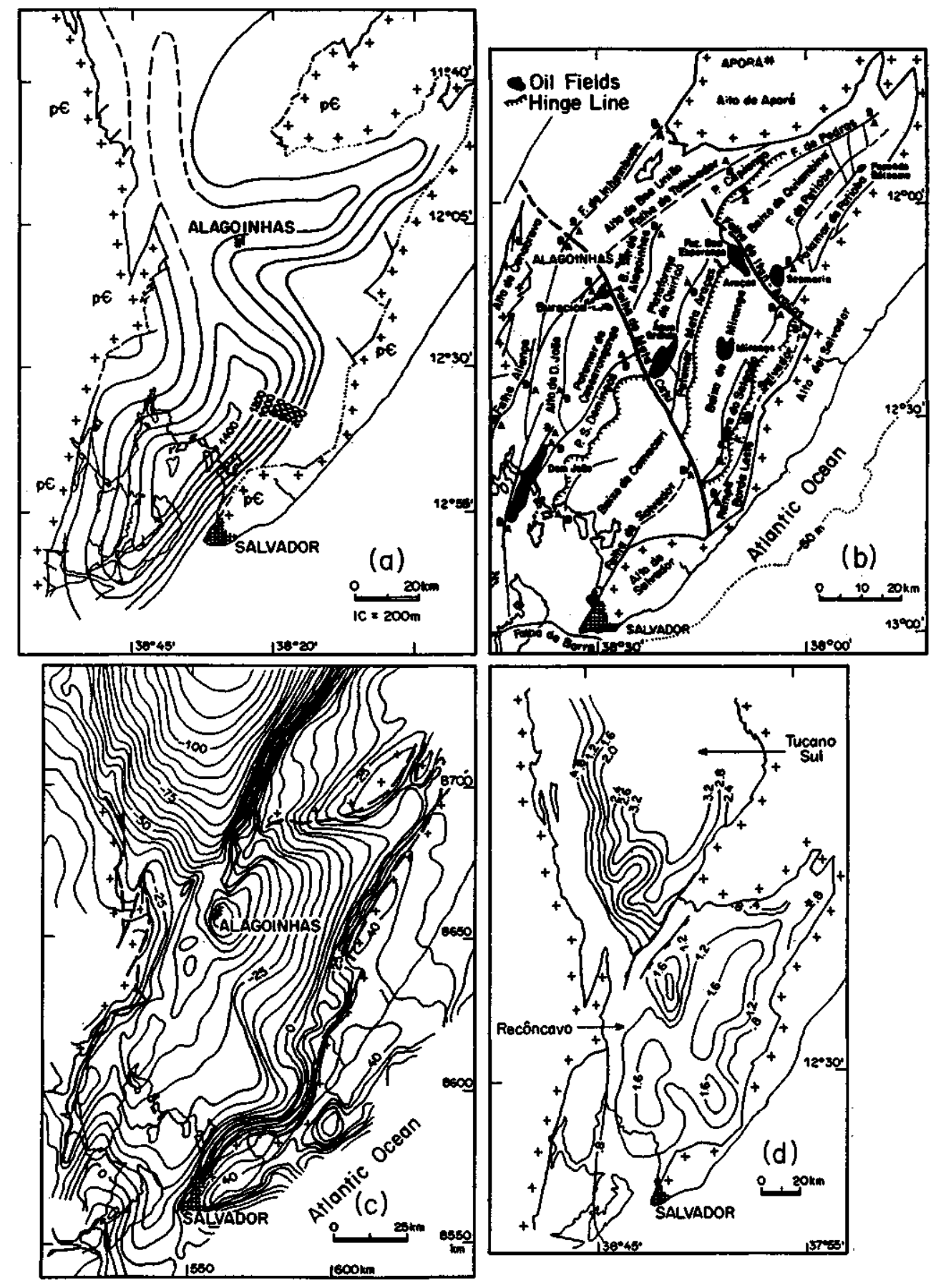

Figura 7 - Variáveis exploratórias utilizadas para avaliação da Bacia do Recôncavo: a) paleoestruturas do embasamento, com indicação das curvas de paleocontorno estrutural no Jurássico (modificado de Carozzi et al. 1976); b) mapa estrutural (modificado de Milani \& Davison 1988); c) mapa bouguer (modificado de Figueiredo et al 1994); d) topo da zona matura, com indicação dos valores de reflectância da vitrinita (modificado de Magnavita et al 1994).

Figure 7 - Exploratory variables used for Recôncavo Basin evaluation: a) basement palaeostructüres, with isodepth curves (modified from Carozzi et al. 1976); b) structural map (modified from Milani \& Davison 1988); c) bouguer map (modified from Figueiredo et al. 1994); d) top of the mature zone, with vitrinite curves (modified from Figueiredo et al. 1994). 
fismo na fácies xisto verde, zona da clorita a início da biotita. A encaixante da mineralização é um metacalcarenito localmente cataclasado, intercalado a metadolomitos micríticos e metamargas carbonosas. Tanto em superfície como em subsuperfície, o principal metalotecto é a proximidade ao contato tectônico entre o Complexo Pelito-Carbonático da Formação Itaiacoca e os xistos do Grupo Setuva, estando as minerali- zações na transição dos mármores para os metapelitos grafitosos, que se comportam como barreiras geoquímicas (ambiente redutor). Os aspectos texturais e mineralógicos das rochas hospedeiras indicam uma concentração inicial sedimentar epigenética, com posterior remobilização devido a duas fases de deformação. A primeira associada a cavalgamento em regime dúctil-rúptil, com transposição generalizada e de-

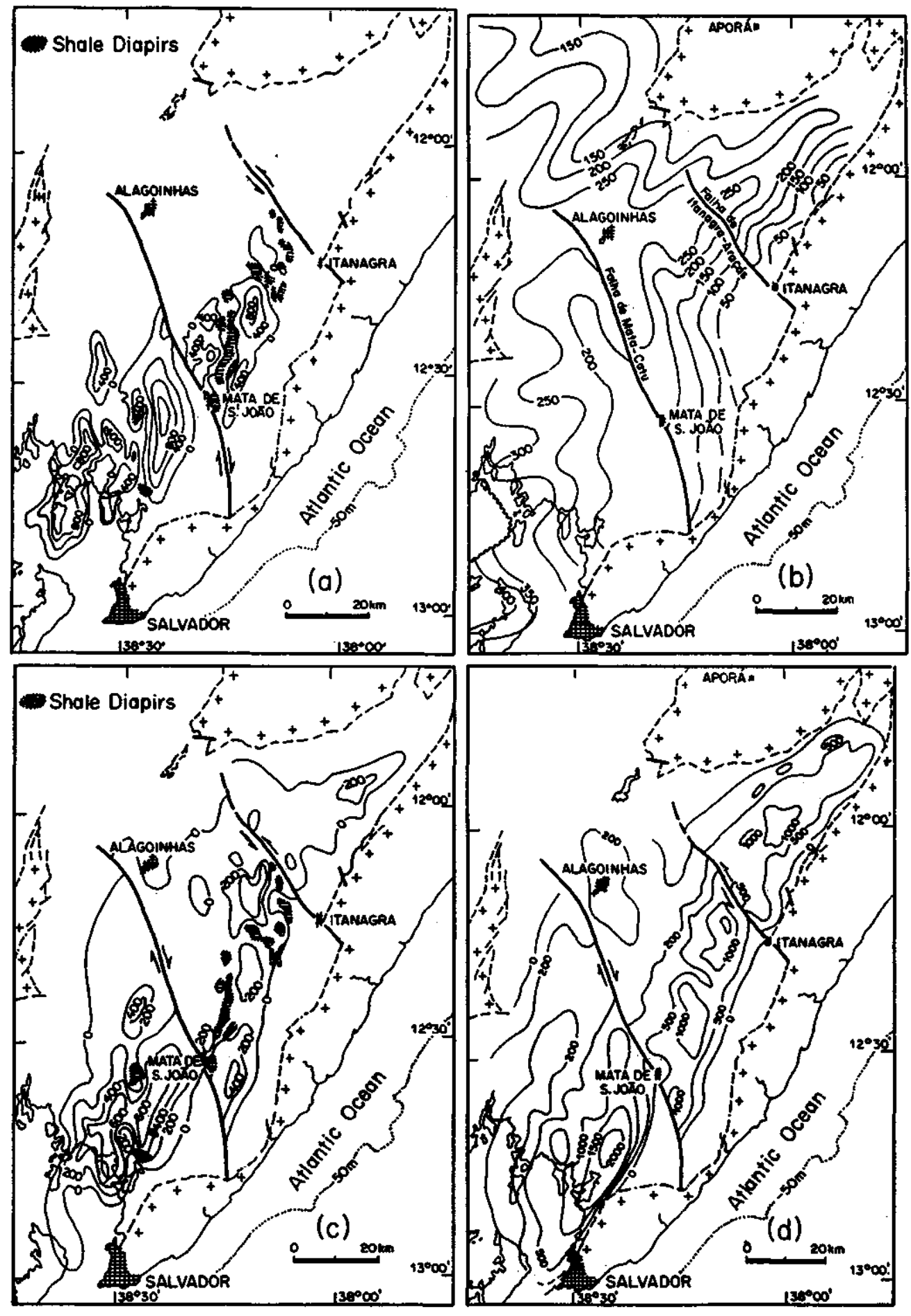

Figura 8 - Variáveis exploratórias utilizadas para avaliação da Bacia do Recôncavo: a - isópacas do Membro Pitanga (modificado de Figueiredo et al. 1994); b - isópacas da Formação Sergi (modificado de Figueiredo et al. 1994); c-isópacas do Membro Caruaçú (modificado de Figueiredo et al. 1994); d - isópacas do Membro Gomo (modificado de Figueiredo et al. 1994). Figure 8 - Exploratory variables used for Recôncavo Basin evaluation: a) Pitanga Member isopachs; b) Sergi Formation isopachs; c) Caruaçú Member isopachs d) Gomo Member isopachs (modified from Figueiredo et al. 1994). 


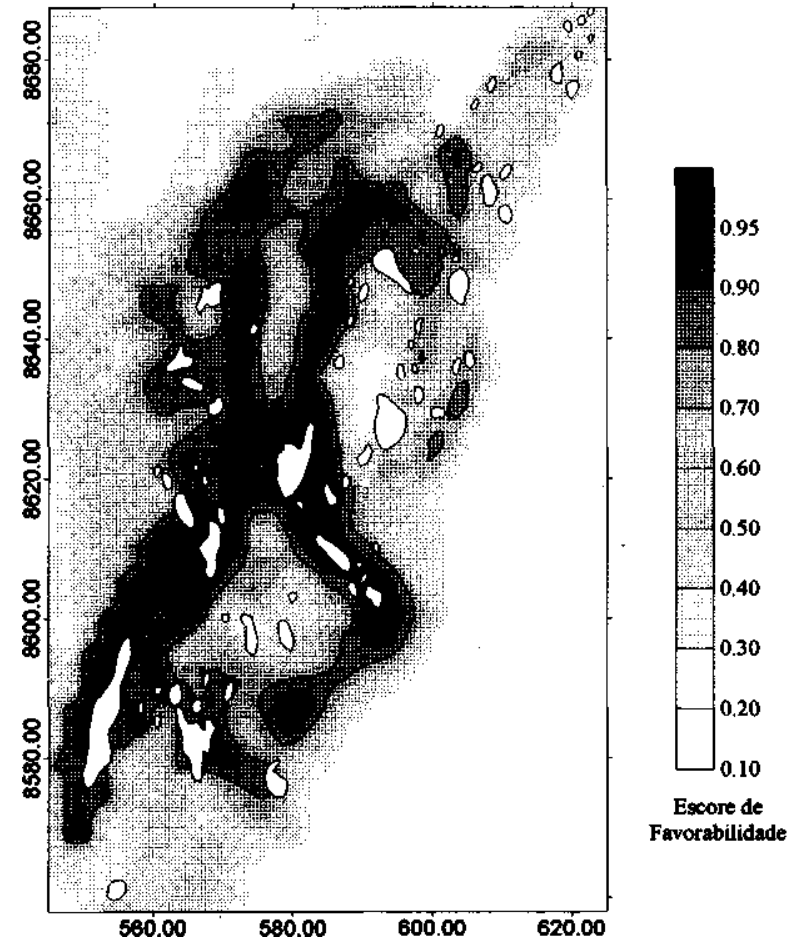

Figura 9 - Mapa de favorabilidade bayesiana para a Bacia do Recôncavo (as áreas destacadas representam os campos conhecidos; Rostirolla et al. 1998).

Figure 9 - Bayesian favorability map of Recôncavo Basin (the signaled áreas represent known fields; Rostirolla et al. 1998).

senvolvimento de uma foliação S1//S0 com indicadores de movimento tectônico para ESE. A segunda por cisalhamento rúptil de alto ângulo, com formação de falhas de empurrão e transcorrências associadas a uma deformação compressiva de ESE para WNW subsequente. Embora Soares et al. (1987) reconhecam a dificuldade em caracterizar a origem dessas mineralizações, a hipótese mais adequada segundo Stevanato (1996) é a de depósito tipo Mississipi Valley ou alternativamente tipo Irlandês (Irish-Type), ambos epigenéticos com modificação tectono-metamórfica.

As variáveis para ponderação compreenderam o mapa de depósitos e ocorrências de minerais de minérios na área, mais seis níveis de informação georreferenciados, isto é: 1) as estruturas da fase de cavalgamento; 2) as falhas da fase de

Tabela l - Resumo das ponderações para a Bacia do Recôncavo, com as variáveis organizadas de acordo com valores decrescentes de importância.

Table 1 - Summary of weighting in Recôncavo Basin, with variables sorted in decreasing importance.

\begin{tabular}{|c|c|c|c|c|c|}
\hline Anslise Bayesidan: & $\boldsymbol{H}^{\circ}$ & w" & $\frac{w^{*}}{w^{*}}$ & Análise de Principutis Compencenles & $\begin{array}{l}\text { Cothetichelcs } \\
\text { do Aulovelor }\end{array}$ \\
\hline 1. Inkerface enurs Áloos e Bajxos & 0.81 & -1.17 & 7.29 & 1. Intcriace entre Allens to Baixos & 0,4342 \\
\hline 2. Baixos Estruturais & 0.77 & \begin{tabular}{|c|c|}
-0.69 \\
\end{tabular} & 4.34 & 2. Mapai Boqucr & 0,4004 \\
\hline 3. Topo da Zopa Matura & 0,90 & $-0,01$ & 3.74 & 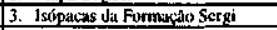 & $-1,381,3$ \\
\hline 4. Isópacas do Membro Caruzañ & 1.10 & -0.12 & 3.37 & 4. Falhas Nommis & 0,3633 \\
\hline 5. Sópacis da Fommisata Screi & 0.46 & -0.56 & 2.79 & 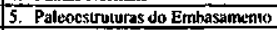 & 10,3580 \\
\hline 6. Mapa Buvquer & 0.33 & -0.62 & 2.57 & 6. Baixns Esiruturais & 10,3030 \\
\hline 7. Fallhas Normais & 0.29 & -0.41 & 2.03 & 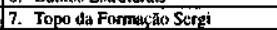 & 0,2179 \\
\hline 8. Isópacas du Mermbru Gomo & 0.51 & $-0,07$ & 1,80 & 8 Allos Esquulurais & 0,2061 \\
\hline 9. Lsopacas do Membra Pilanga & 0.51 & -0.03 & 1,72 & 9. Topo da Zona Malura & 0.1976 \\
\hline 10. Palecesscruluras do Embosamento & 0.21 & -0.22 & 1.55 & 10. hispacas do Mcumbro Pilanged & 10,0527 \\
\hline 11. Aloss Estnuturais & 0.28 & -10.12 & $1.4 \mathrm{x}$ & 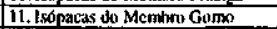 & 10,0506 \\
\hline 12. Topo da Formacta Sergi & 0.11 & $-0,09$ & 1,23 & 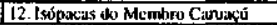 & 0,0405 \\
\hline
\end{tabular}

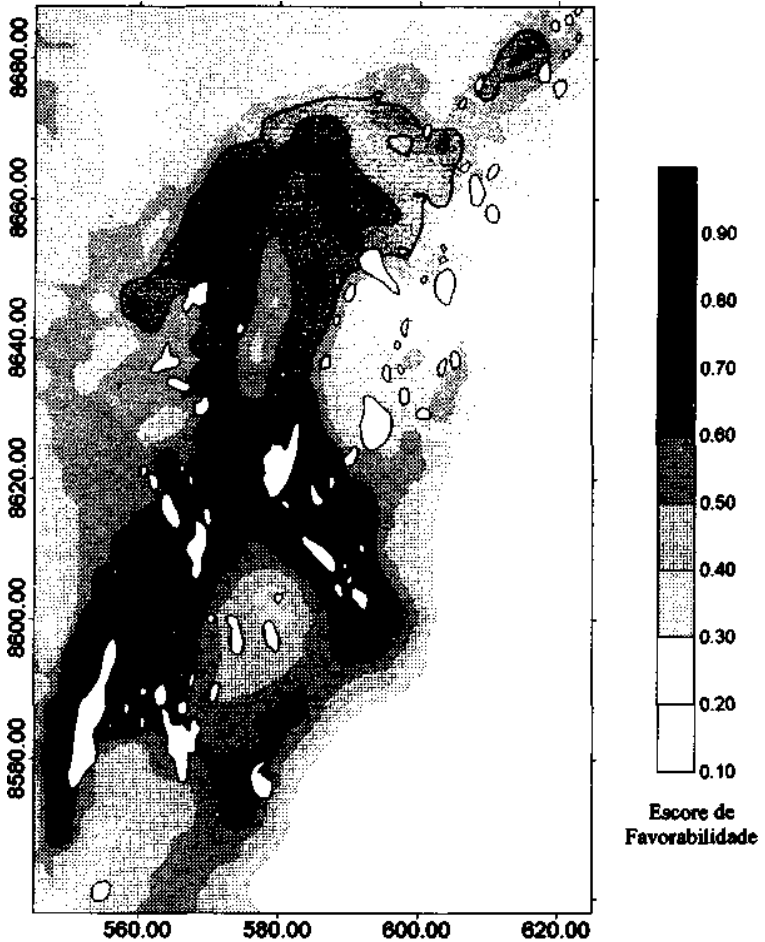

Figura 10 - Mapa de favorabilidade multivariada para a Bacia do Recôncavo (as áreas destacadas representam os campos conhecidos; Rostirolla et al. 1998).

Figure 10 - Multivariate favorability map of Recôncavo Basin (the signaled áreas represent known fields; Rostirolla et al. 1998).

empurrão, 3) as lentes carbonáticas com metadolarenitos, 4) os metapelitos com intervalos carbonosos, 5) o mapa aerogeofísico com valores krigados de Contagem Total (aerocintilometria - CT) e 6) a superfície de tendência de 3a. ordem dos dados geoquímicos de solo (Fig. 12).

Os dados estruturais e litológicos foram obtidos diretamente do mapa geológico de semi-detalhe (Soares et al. 1987), com informações adicionais de Stevanato e Soares (com. verbal). A informação aerogeofísica foi utilizada como critério permissivo na forma de mapa de contorno, elaborado a partir de dados do canal CT do projeto Aerogeofísico Serra do Mar Sul (CPRM 1978, apud Stevanato 1996), tendo sido escolhido o intervalo de 200 a 275 contagens por segundo (cps) para transformação em evidência presente ou ausente, conforme a exigência do método. Para os dados geoquímicos, em função da dependência condicional entre $\mathrm{Cu}, \mathrm{Pb}$ e $\mathrm{Zn}$, foram selecionadas somente as anomalias para $\mathrm{Pb}$, com a distribuição espacial sendo obtida a partir do ajuste de uma superficie de tendência de $3 a$. ordem $\left(r^{2}=0,54\right)$. Para discriminar tal distribuicão como variável exploratória, foi utilizado 0 valor da média do $\mathrm{Pb}$, em valores logaritmos $(\mu=4,22 ;$ Fig. 12$)$.

Em virtude do razoável nível de desenvolvimento do modelo prospectivo (Stevanato 1996), na área de Palmeirinha não se observa uma diferença acentuada nos pesos atribuídos a cada variável comparando-se os dois métodos, com exceção da variável "mapa aerogeofisico" que apresenta a $3^{\mathrm{a}}$ importância no método multivariado, em contraposição à $5^{\text {a }}$ colocação no procedimento bayesiano (tabela 2). A análise integrada resultou no delineamento de alvos coincidentes em ambos os procedimentos de quantificação (Figs. 13 e 14), com o melhor trend de favorabilidade ocorrendo segundo uma faixa aproximadamente norte-sul que contém a seção basal do Complexo Pelito-Carbonático, próxima à Falha do Rio Itararé nas porções leste e sudoeste da área. Um trend secundário de favorabilidade é possível distinguir como pequena faixa na 
porção centro-oeste, que nos trabalhos de prospecção ainda não haviam sido discriminados como alvos de pesquisa. $\mathrm{O}$ trend norte-sul principal ajusta-se, em grande parte, aos locais onde se pretendia continuar com programas de prospecção de detalhe, principalmente nos setores destacados com as letras a, $b$ e $c$ na figura 13. Os resultados das ponderações mostram que a maior influência deve-se às variáveis litoestruturais, principalmente as lentes de mármores e as falhas de cavalgamento.

CONCLUSÕES Embora o trabalho tenha enfocado a quantificação de dados, ficou evidente que a análise qualitativa dos mesmos é uma etapa crítica para a avaliação adequada de favorabilidade. A metodologia é uma aprendizagem por tentativa-e-erro, tendo em vista a possibilidade de um contínuo aperfeiçoamento durante a organização e a renovação do conhecimento, auxiliando na tomada de decisões em exploração. Estabelece restrições (constraints) aos modelos de depósitos adotados e complementa os critérios decisórios tradicionais, tais como sentimento, crença, experiência prévia, histórico de sucesso, confiança nos dados e fatores sócioeconômicos.

A caracterização metalogenética é, sem dúvida, uma etapa importante para auxiliar a prospecção. Todavia, os prospectos, como alvos que devem ser considerados pelas empresas da indústria mineral, somente são atrativos caso sejam quantificadas adequadamente as áreas favoráveis para ocorrência de novos depósitos. Sabe-se que o investimento em exploração mineral é muito seletivo, especialmente por seu elevado risco e demorado retorno, e que numa província mineral conhecida, uma tecnologia nova de descoberta, com o auxílio da avaliação de favorabilidade, apresenta vantagens competiti-
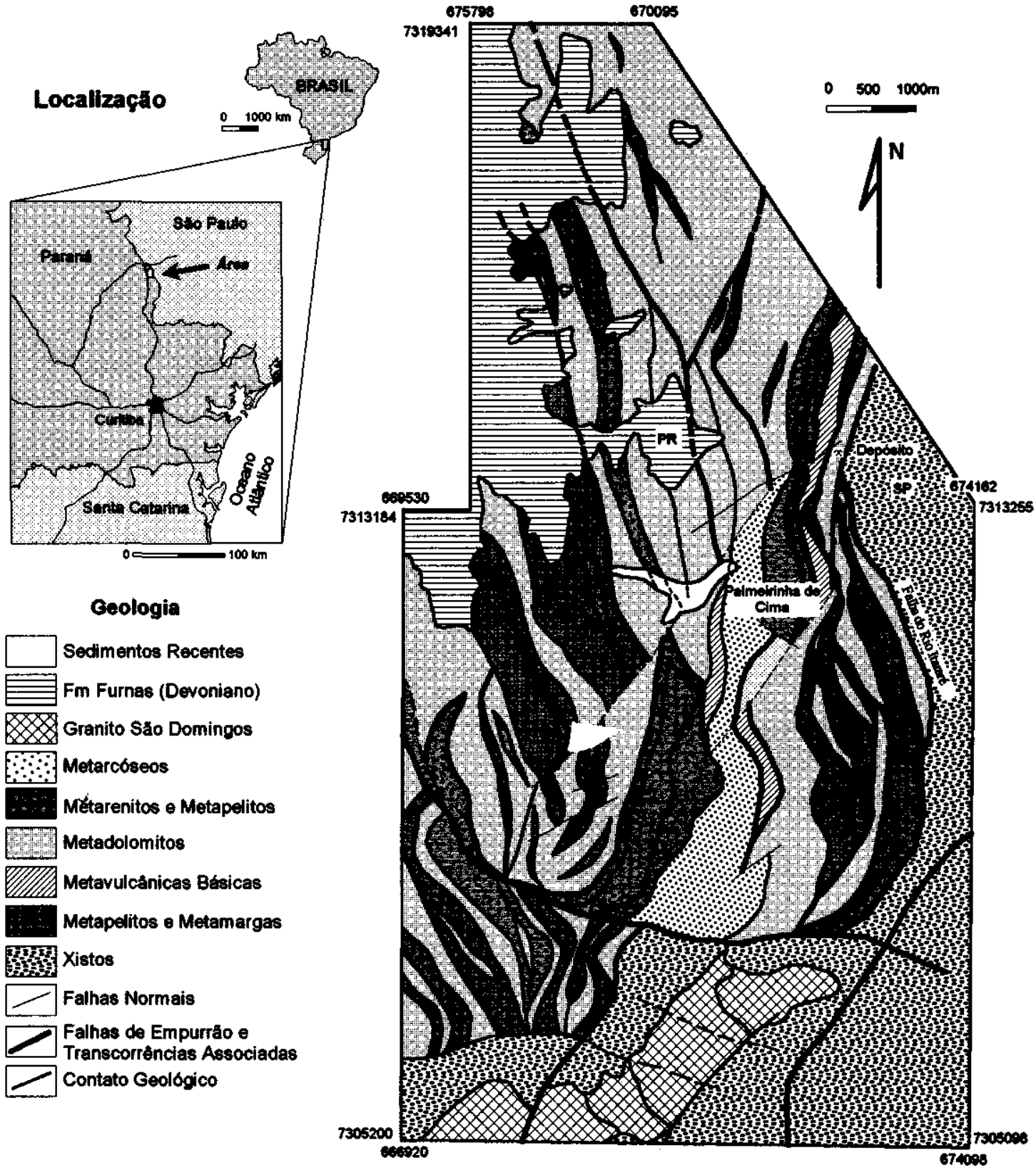

Figura 11 - Localização e mapa geológico da área de Palmeirinha/Sengés, Faixa Itaiacoca-PR, com a indicação do depósito de Pb conhecido (modificado de Soares et al. 1987 e Stevanato 1996).

Figure 11 - Location and geological map of Palmeirinha-Sengés, Itaiacoca Formation, with indication of Pb deposit (modified from Soares et al. 1987). 
vas sobre modelos prospectivos clássicos, com base somente em técnicas de busca convencionais. Dessa forma, como normalmente é manipulado um grande volume de dados e conceitos, a utilização da avaliação de favorabilidade pode otimizar o uso do conhecimento, auxiliando no estabelecimento das incertezas e na análise da probabilidade de sucesso.

$\mathrm{Na}$ representação espacial e análise das informações sobre o alvo exploratório, estabelece-se como ideal a seguinte sequência de atividades: 1) mapear a área e construir o banco de dados georreferenciados; 2) descrever os depósitos conhecidos e elaborar o modelo de ocorrência; 3) montar o modelo genético e caracterizar as variáveis diagnosticas; 4) aplicar as regras de inferência estatística; 5) calcular os ponderadores para cada variável diagnostica; 6) integrar os mapas ponderados; 7) construir os mapas de favorabilidade e 8) analisar os resultados e a eficiência do sistema de avaliação.

Esses procedimentos, fundamentados na quantificação de ponderadores bayesianos e multivariados, foram testados em duas áreas distintas quanto aos aspectos de evolução geológica e potencial exploratório. Na avaliação da Bacia do Recôncavo, os dois métodos de ponderação priorizaram áreas favoráveis distintas, entretanto ambos destacararrüocais ainda com poucas descobertas: à norte do campo de Água grande e entre os campos de Taquipe e Dom João. Na avaliação da Faixa Itaiacoca, a análise segundo as duas técnicas estatísticas delineou áreas favoráveis coincidentes. $\mathrm{O}$ resultado demonstra a aplicabilidade da metodologia proposta, além da importância da elaboração de um modelo de depósito confiável nas etapas anteriores à quantificação.

Agradecimentos $\mathrm{O}$ autor agradece o apoio financeiro da PETROBRÁS e da FINEP/PADCT projeto n. $65958001 \mathrm{e}$

(a)

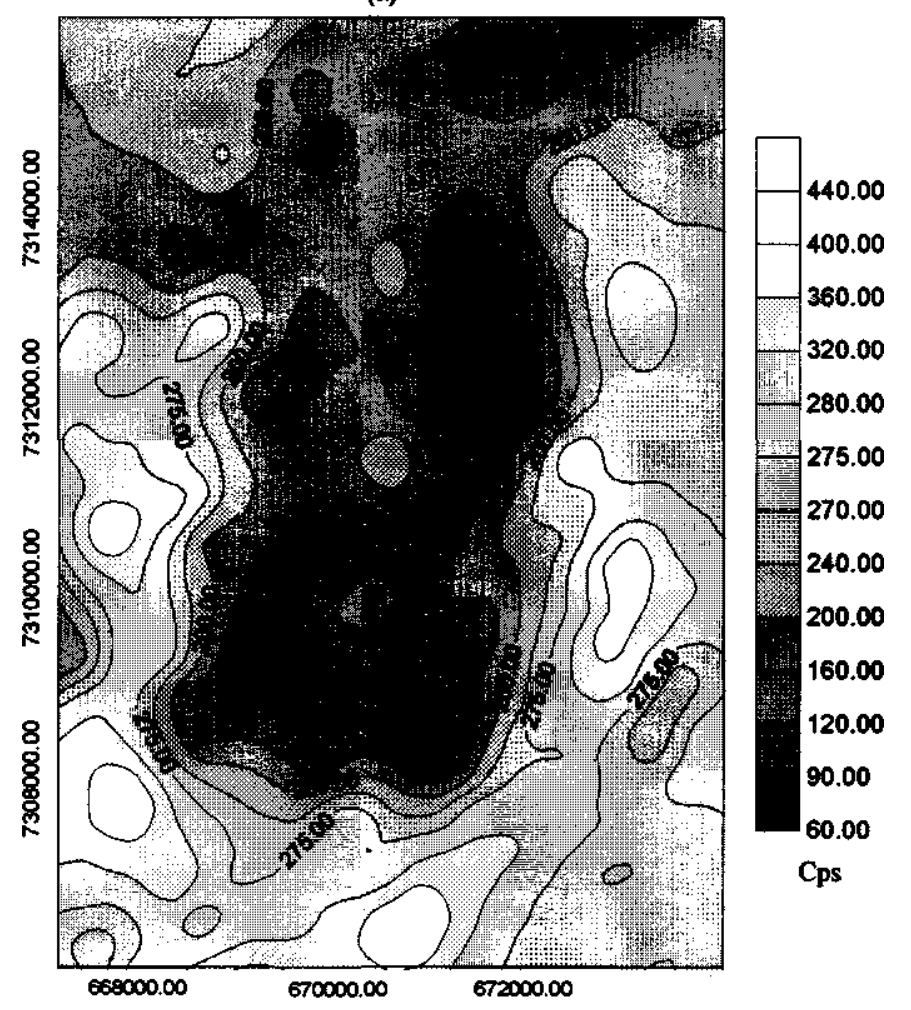

Tabela 2 - Síntese das ponderações para a área de Palmeirinha, Faixa Itaiacoca, com as variáveis organizadas de acordo com valores decrescentes de importância.

Table 2 - Summary of weighting in Palmeirinha area, with variables sorted in decreasing importance.

\begin{tabular}{|c|c|c|c|c|c|}
\hline Anallise Baycsiant & $w^{*}$ & $\boldsymbol{w}^{-}$ & $\frac{w^{*}}{w^{*}}$ & Análise de Principais Componemes & \begin{tabular}{|l|} 
Cocincientes \\
do Autovelor
\end{tabular} \\
\hline L. Márnures com netadolartanilos & 1.36 & -0.99 & 10.51 & I. Marrmoresc com mel adod arentilos & 0,54 \\
\hline 2. Emporinges da baixo Ingulo & 1.25 & -0.99 & 9.46 & 2. Empurüess de baixo àngulo & 0.52 \\
\hline 3. Molupelilos cartonosos & 1.10 & -0.48 & 4.84 & 3. Mapa Acroge offico & 0.44 \\
\hline 4. Anomalias Geoquínicu (Pb) & 067 & -1.29 & 2.60 & 4. Metapelitos carbonosos & 0.35 \\
\hline 5. Mapa Aerogeofístcó & 0.51 & -4.42 & $\frac{1.53}{2.53}$ & 5. Anomalias Gequuimicas (Pb) & 0.33 \\
\hline 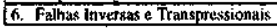 & 0.39 & 10.0 & 1.60 & 16. Fallhas Lthertrast $\mathrm{t}$ Transopessionals & 0.12 \\
\hline
\end{tabular}

concessão de uma bolsa do CNPq para custear parcialmente o trabalho. Agradece também a UFPR, pelo apoio institucional, e as participações efetivas do Prof. Dr. Chang Hung Kiang e do Prof. Dr. Paulo César Soares, com a troca de idéias sobre o tema e revisão do texto. Do mesmo modo, agradece ao Prof. Dr. João Carlos Biondi, ao geólogo Maximilian Forlin e ao Prof. Dr. Mário Luís Assine, pelo auxílio na revisão e correção; ao geólogo Rodoílton Stevanato, por ter cedido os dados sobre a região de Palmeirinha e ao Dr. Augustinho Rigoti pelo correção do abstract. Um agradecimento especial deve ser dado ao Dr. Nilo Chagas de Azambuja Filho e ao Dr. Francisco Nepomuceno Filho, pela motivação e decisão de aprovar o financiamento de uma parcela do trabalho. Agradece também ao geólogo Flávio Luís Fernandes pelo empréstimo de artigos técnicos e aos Profs. Drs. Paulo Milton Barbosa Landim e Dr. José Ricardo Sturaro, pelas sugestões.

(b)

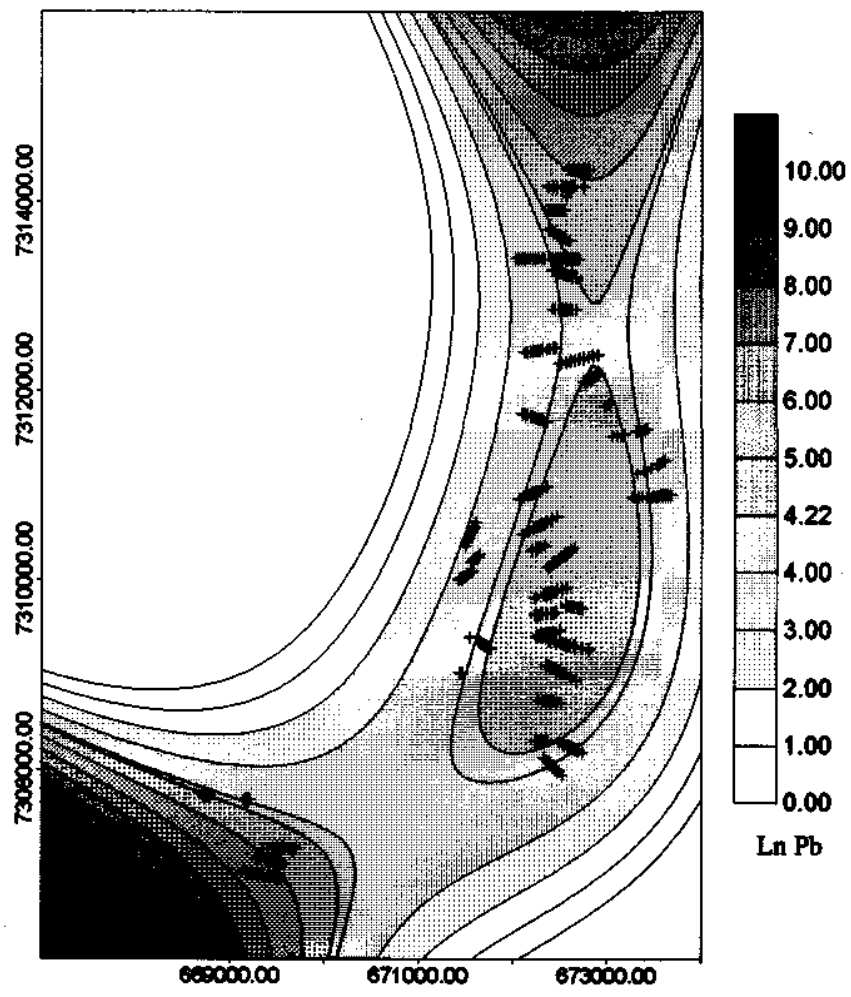

Figura 12 - (a) Mapa aerogeofísico com valores krigados de contagem total da área de Palmeirinha e (b) Superficie de tendência de $3^{a}$. ordem com a distribuição dos dados geoquímicos de Pb (as cruzes alinhadas representam os perfis de solo).

Figure 12 - (a) Aero-geophysical map with krigged total counting of Palmeirinha area and (b) Third-order trend surface with Pb geochemical data (The aligned crosses represent the soil profiles). 


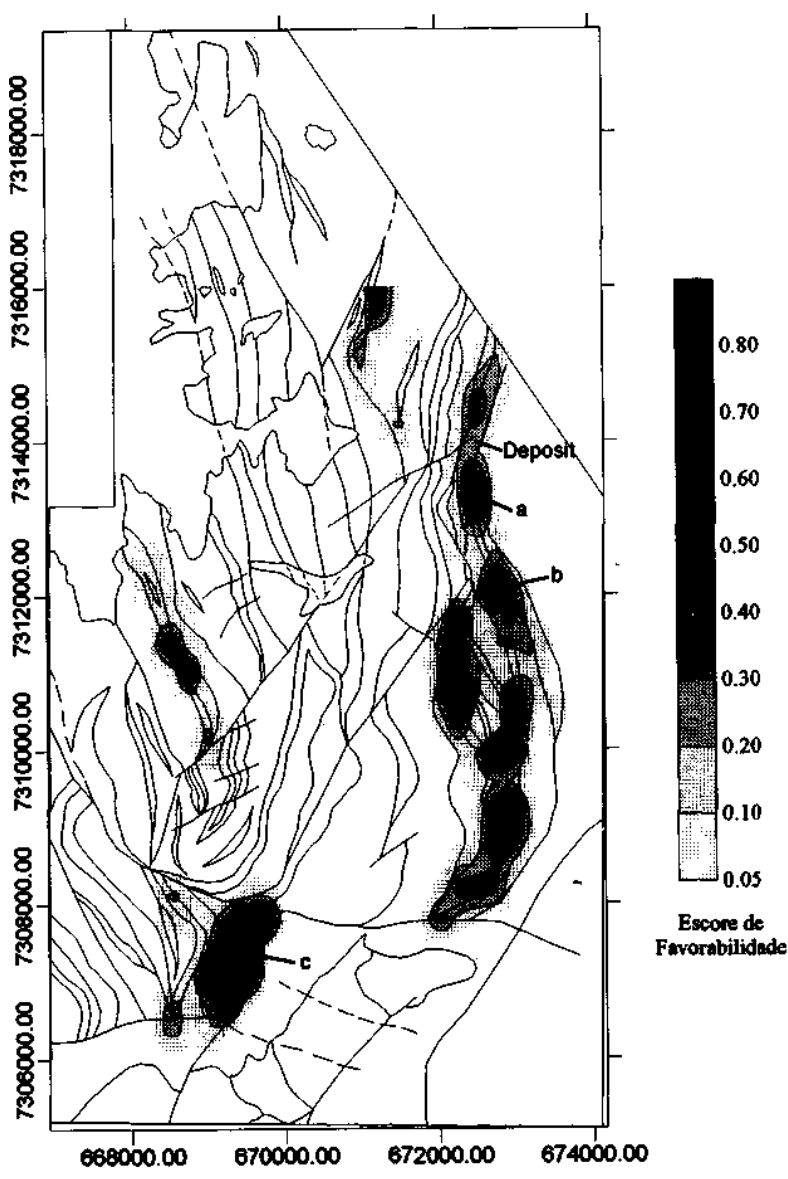

Figura 13 - Mapa defavorabilidade bayesiana para depósitos de Pb-Zn na área de Palmeirinha (Rostirolla et al. 1998). Figure 13 - Bayesian favorability map for Pb-Zn deposits in Palmeirinha (Rostirolla et al 1998).

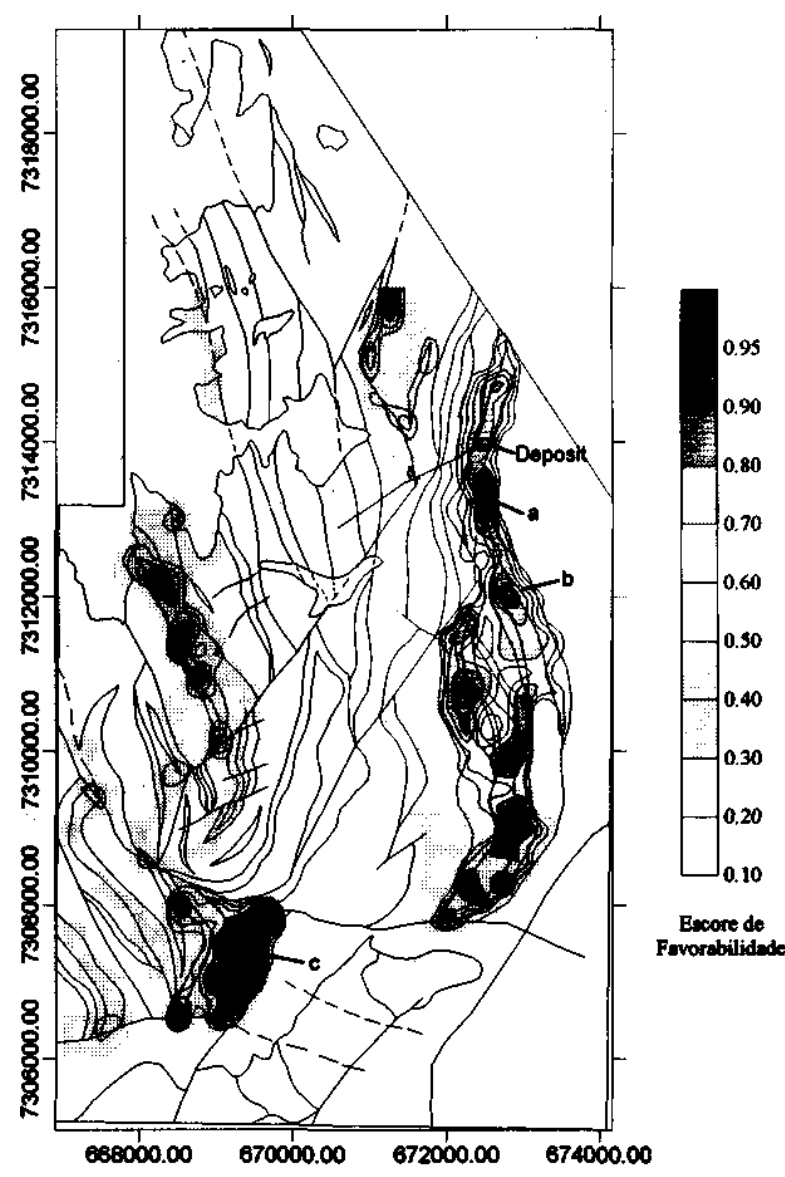

Figura 14 - Mapa de favorabilidade multivariada para depósitos de Pb-Zn na área de Palmeirinha (Rostirolla et al. 1998).

Figure 14 - Multivariate favorability map for $\mathrm{Pb}-\mathrm{Zn}$ deposits in Palmeirinha (Rostirolla et al. 1998).

\section{REFERÊNCIAS}

Adams,S. 1986. Using geological Information to develop exploration strategies for epithermal deposits. In: Epithermal Deposits, Chapter 12, p.273-298.

Agterberg, F.P. 1989. Systematic approach to dealing with uncertainty of geoscience information in mineral exploration. In: APCOM Symposium, 21, Las Vegas. Proceedings: 165-178.

Bonham-Carter, G.F.; Agterberg, F.P; Wright, D.F. 1989. Weights of evidence modelling: anew approach to mapping mineral potential. Geological Survey of Canada, Paper n.89-9, p. $171-183$.

Carozzi, A.V.; Araújo, M.B.; Césero, P.; Fonseca, J.R.; Silva, V.J.L. 1976. Formação Salvador: um modelo de deposição gravitacional subaquosa. Boletim Técnico da Petrobrás, Rio de Janeiro, 19:47-79.

Carr, J.R. 1995. Numerical analysis for the geological sciences. New Jersey: Prentice-Hall, $592 \mathrm{p}$.

Cox, D.P.; Singer, D.A. (eds) 1986. Mineral Deposit Models. U.S. Geological Survey Bulletin.1693, $379 \mathrm{p}$.

Figueiredo, A.M.F.; Braga, J.A.E.; Zabalaga, J.C.; Oliveira, J.J.; Aguiar, G.A.; Silva, O.B.; Mato, L.F.; Daniel, L.M.F.; Magnavita, L.P.; Bruhn, C.H.L. 1994. Recôncavo basin, Brazil: a prolific intracontinental rift basin. The American Association of Petroleum Geologists Memoir n.59, p.157-203.

Harff, J.; Davis, J.C. 1990. Regionalization in geology by multivariate classification. Malhem. Geology, 22:573-588.

Henley, R.W.; Berger, B.R. 1993. What is an exploration model anyway? - an analysis of the cognitive development and use of models in mineral exploration. Geological Association of Canada Special Paper n.40, p.41-50.

Hugget, R.J. 1985. Earth surface systems. Berlin: Springer-Verlag, 270 p.

Magnavita, L.P.; Davison, I.; Kusznir, N.J. 1994. Rifting, erosion, and uplift history of the Recôncavo-Tucano-Jatobá Rift, northeast Brazil. Tectonics, 13(2):367-388.

Magoon, L.B.; Dow, W.G. 1994. The petroleum system. AAPG Memoir n.60, p. 3-24.

McCammon, R.B.; Botbol, J.M.; Sinding-Larsen, R.; Bowen, R.W. 1983 Characteristic analysis - 1981: final program and a possible discovery. Mathematical Geology, 15:59-83.
Mathematical Geology, 15:59-83.

Mello, M.R.;Mohriak, W.U.; Koutsoukos, E.A.M.; Bacoccoli, G. 1994. Selected petroleum systems in Brazil. The American Association of Petroleum Geologists Memoir n.60, p.499-512.

Milani, E.J. 1987. Aspectos da evolução tectônica das bacias do Recôncavo e Tucano-Sul, Bahia, Brasil. Ciência-Técnica-Petróleo, Rio de Janeiro, n. 18, $61 \mathrm{p}$.

Milani, E.J.; Davison, I. 1988. Basement control and transfer tectonics in the Recôncavo-Tucano-Jatobá Rift, Northeast Brazil. Tectonophysics, n. 154, p.41-70.

Mosier, D.L.; Bliss, J.D. 1992. Introduction and overview of mineral deposit modeling. US Geological Survey Bulletin n.2004, p. 1-5.

Pan, G.; Porterfield, B. 1995. Large-scale mineral potential estimation for blind precious metal ore bodies. Nonrenewable Resources, 4:187-207.

Rostirolla, S.P.; Soares, P.C.; Chang H.K. 1998. Bayesian and multivariate methods applied to favorability quantification in Recôncavo Basin and Ribeira Belt, Brazil. Nonrenewable, 7(1):7-24.

Rostirolla, S.P.; Soares, P.C.; Stevenato, R. 1996. Alguns aspectos da análise sistémica aplicada à exploração: sistema petrolífero versus sistema formador de minério. In: Congresso Brasileiro de Geologia, 39. Anais... Salvador, BA, SBG, 5:225-228

Soares, P.C.; Stevenato, R.; Camargo, C.R. 1987. Geologia do nordeste da Faixa Itaiacoca - Paraná. In: Simpósio Sul-Brasileiro de Geologia, 3., 1987. Atas... Curitiba: SBG, p.245-262

Stevanato, R. 1996. Minuta de dissertação de mestrado. Dissertação de Mestrado, Departamento de Geologia, Curitiba: UFPR.

Stevenato, R.; Soares, P.C.; Camargo, C.R. 1991. Descoberta de um novo depósito mineral de $\mathrm{Pb}$ e $\mathrm{Zn}$ no estado do Paraná -Formação Itaiacoca. In: Simpósio

Manuscrito A917

Recebido em 03 de junho de 1997

Revisão do autor em 18 de novembro de 1997 Revisão aceita em 26 de novembro de 1997 de Geologia do Sudeste, 2. Atas... São Paulo: SBS/SP-RJ. p.197-204. 